\title{
ARTÍCULO
}

\section{Posthumano y Filosofía del Derecho. Una mirada crítica a la teoría de Rosi Braidotti ${ }^{1}$ \\ Posthuman and Philosophy of the law. A critical vision of the Rosi Braidotti's theory}

\author{
Lucia Aparicio Chofré \\ Profesora Asociada. Departamento de Filosofía del Derecho y Política. Universidad de Valencia \\ Profesora titular. Facultad de Ciencias Sociales. Universidad Europea de Valencia
}

Fecha de recepción 11/06/2019 | De aceptación: 01/12/2019 | De publicación: 27/12/2019

\section{RESUMEN.}

El presente artículo presenta una visión crítica de la contribución de la filósofa Rosi Braidotti a la elaboración de algunos de los conceptos filosóficos contemporáneos, en especial de sus conceptos de identidades nómadas y de posthumano. Una teoría en la que se reivindica la necesidad de una responsabilidad "posthumana" en la que resulta relevante la aportación de la Filosofía del Derecho a cuestiones tan actuales como son el reconocimiento de derechos de los animales, el control masivo de personas a través de la vigilancia electrónica o la modificación de la identidad sexual en adolescentes.

\section{PALABRAS CLAVE.}

posthumano, identidades nómadas, resistencia, vulnerabilidad interseccional, modificación de la identidad sexual, vigilancia electrónica y derechos de los animales

\section{ABSTRACT.}

In this article, I will propose some criticisms against Rosi Braidotti theory about "Posthumanism" and "nomad ethics". Braidotti's theory vindicates the need for a "posthuman" responsibility towards both silenced minorities that strives for recognition, and animals. I will argue that her theory needs the support of legal theory in order to face issues such as the recognition of animals' rights, the massive control through Internet or the modification of sexual identity in adolescents.

\section{KEY WORDS.}

Posthumanism, nomad identities, resistance, intersectional vulnerability, modification of their sexual identity, electronic surveillance and animal rights.

\footnotetext{
${ }^{1}$ Me gustaría agradecer a los profesores Francesco Biondo y Pilar Valor por guiarme en la comprensión de algunos de los conceptos postestructuralistas empleados y en la revisión y corrección del texto.
} 
Sumario: 1. Introducción: El concepto de posthumano en Braidotti 2. La relación entre el hombre y el animal. El derecho y la responsabilidad del hombre en relación con el mundo viviente 3. ¿Qué capitalismo? Algunas distinciones relevantes 4. ¿Puedo elegir mi identidad sexual (si soy un menor)? 5. Conclusión

\section{Introducción: El concepto de posthumano en Braidotti}

La filosofa Rosi Braidotti ocupa un lugar destacado en el mundo de los estudios sobre el feminismo contemporáneo y en general en el variado universo de las teorías postestructuralistas de las ciencias humanas. Se trata de una discípula de Foucault, Deleuze y Guattari que ha tratado de aplicar la compleja herencia filosófica de estos autores al debate actual sobre la identidad de género y el feminismo, pero también al estatuto epistemológico de las ciencias humanas postcoloniales y a las teorías críticas de cuño postestructuralista ${ }^{2}$.

Por motivos obvios de espacio no podemos analizar en profundidad la contribución de esta autora a las temáticas de género y a las teorías feministas. Ni tampoco desarrollar a fondo la compleja operación cultural que la autora lleva a cabo desde su libro Patrones de disonancia (Patterns of dissonance 1991), como es la de elaborar una teoría materialista y monista, que debe mucho al magisterio de Baruch Spinoza, que escapa a la reducción del sujeto agente como hombre, occidental, heterosexual y propietario. Un sujeto que se encuentra encorsetado en una estructura que le viene dada y que solo puede aceptar y a la cual ha de conformar sus deseos. Por tanto, un sujeto que debe conformarse con relaciones omnipresentes que se desarrollan en cualquier ámbito de las relaciones sociales (desde la familia a las instituciones educativas, de la tecnología a la formación del saber humanístico, de la formación de la identidad sexual a la producción de los deseos determinados por las exigencias del consumo) y de las cuales no puede escapar. Desde este punto de vista, la autora, como es conocido, se inspira continuamente en Foucault. Su teoría rinde un homenaje a la idea del filósofo

\footnotetext{
${ }^{2}$ Rosi Braidotti (Latisana, 1954) es catedrática de Filosofía y directora del Centro para las Humanidades de la Universidad de Utrecht. Nacida en Italia, creció en Australia, donde se licenció en la Universidad Nacional de Australia en Canberra, y realizó sus estudios de doctorado en Filosofía en la Sorbona (París). Desde 1988 ha sido profesora en la Universidad de Utrecht. Considerada como una de las pioneras en los estudios europeos de la mujer, su carrera ha recibido múltiples reconocimientos, como son el doctorado honoris causa de la Universidad de Linköping (Suecia, 2013) y de la Universidad de Helsinki (2007) y el Premio Erasmus de la Comisión Europea (2010). Entre sus obras de referencia, algunas de ellas traducidas al castellano, destacan: Sujetos nómadas (Paidós-Argentina, 2000), Metamorfosis, Hacia una teoría materialista del devenir (Akal, 2003), Feminismo, diferencia sexual y subjetividad nómada (Gedisa, 2004), Transposiciones (Gedisa 2009), Lo Posthumano (Gedisa, 2015) y Posthuman ecologies (2018). Para ampliar la información sobre esta autora se puede consultar su propia página web disponible en el siguiente enlace: https://rosibraidotti.com/ (última consulta 7 de junio de 2019).
} 
francés de la "muerte del hombre", esto es: el final de una forma de humanismo ingenuo, en la que el sujeto podía engañarse creyendo que era el fruto de una serie de decisiones conscientes, y, por lo tanto, podía desvincularse, juzgar y controlar estructuras complejas, como las instituciones, las políticas públicas, las ideologías e incluso los $\operatorname{deseos}^{3}$. La autora construye una atractiva mezcla entre los estudios feministas, anticoloniales, postestructurales y materialistas y, además, elabora unos estudios pioneros en relación con las interacciones existentes entre los seres humanos y las máquinas y también entre los seres humanos y el medioambiente. Respecto a esta última cuestión, resulta decisiva la influencia y la relectura de Spinoza, que realiza a través de Deleuze y Guattari, como una relación que transforma la propia imagen del sujeto agente, no solo como un ente biológicamente determinado sino también como un sujeto que en parte construye su propio cuerpo.

Con esta destacada producción, la autora trata de huir de los resultados pesimistas de las teorías estructuralistas de la "muerte del hombre", que llevan a ignorar cualquier posibilidad de resistencia ante dichas estructuras de poder. Para Braidotti, en cambio, el sujeto padece naturalmente estas estructuras: el mercado y sus procesos; el Estado y sus leyes; la cultura y sus definiciones; el pensamiento filosófico y sus categorías. Pero para cada una de estas estructuras, sin embargo, según la autora se contrapone una resistencia por parte de los sujetos, que a través de sus deseos intentan huir y construir su propia subjetividad a través de prácticas de resistencia que construyen identidades “nómadas". Nómadas en cuanto que escapan de las estructuras antes mencionadas. La investigación y la descripción de dichas prácticas de resistencia conectan sus raíces postestructuralistas con el feminismo, los estudios de género y los estudios postcoloniales. Su teoría constituye una apuesta a favor de una teoría crítica anti antropocéntrica, monista, materialista y vitalista pero no pesimista sobre la posibilidad de una resistencia ante estas estructuras de poder omnipresentes. Y tal apuesta, sobre la potencial crítica y resistencia frente a procesos infinitos de construcción de la identidad colectiva, toma forma en dos de sus obras más conocidas como son Transposiciones (edición inglesa de 2006) y, posteriormente, Lo Posthumano (edición inglesa de 2012).

El término "posthumano" a menudo se emplea como un sinónimo de "transhumano", haciendo que se planteen una serie de cuestiones de no poco calado. Dicho planteamiento lo encontramos entre

\footnotetext{
${ }^{3}$ Sobre el legado de Foucault existe una enorme literatura, de la que se puede destacar desde una perspectiva histórica a DOSSE, F.; Historia del estructuralismo, vol. 1, (1992), trad. castellana de M. del Mar Llinares, Akal, Madrid, 2004, cap. 34, pp- 370-384, y vol. II (1992), trad. castellana Akal, Madrid, 2004 cap. 23 y 32.
} 
algunos de los denominados "instigadores del miedo", en especial en el ámbito político, que, pretenden aglutinar muchísimos votos, apelando a la desconfianza empleando fenómenos como la inmigración, la experimentación genética o la integración económica supranacional.

Pero este temor no se puede reducir solo a una opinión pública cada vez más influenciada por las redes sociales, como Facebook o Twitter que, contradiciendo su promesa de conectar el mundo, refuerzan los prejuicios y las identidades en conflicto. Nos enfrentamos, más bien, a la posibilidad de que la biotecnología ${ }^{4}$ y el uso de las plataformas electrónicas ${ }^{5}$ lleve al ocaso al humanismo liberal, que cree en el libre albedrio, en el reconocimiento de espacios de privacidad y en la igualdad biológica de los seres humanos. Yuval Harari (2016) en relación con esta cuestión afirma en su conocido best seller Homo Deus, Breve historia del futuro:

"Los grandes proyectos humanos del siglo XX (superar el hambre, la peste y la guerra) pretendian salvaguardar una norma universal de abundancia, salud y paz para toda la gente, sin excepción. Los nuevos proyectos del siglo XXI (alcanzar la inmortalidad, la felicidad y la divinidad) también esperan servir a toda la humanidad. Sin embargo, debido a que estos proyectos aspiran a sobrepasar la norma, no a salvaguardarla, bien podrían derivarse en la creación de una nueva casta superhumana que abandone sus raíces liberales y trate a los humanos normales no mejor que los europeos del siglo XIX trataron a los africanos.

Si los descubrimientos científicos y los avances tecnológicos dividen a la humanidad en una masa de humanos inútiles y una pequeña élite de superhumanos mejorados o si la autoridad se transfiere completamente a algoritmos muy inteligentes, el liberalismo se hundirá. ¿Qué nuevas religiones o ideologías podrían llenar el vacío resultante y guiar la evolución subsiguiente de nuestros descendientes casi divinos?" 6

\footnotetext{
${ }^{4}$ En este sentido y exclusivamente a modo de ejemplo se puede citar a FUKUYAMA, F.; El fin del hombre: consecuencias de la revolución biotecnológica (2002), trad. castellana de P. Reina, ediciones B, Barcelona, 2002; SANDEL, M.; Contra la perfección, trad. castellana de R. Vilà Vernis, Marbota ed., Barcelona, 2007. En relación con el extenso debate sobre la justificación moral de la utilización de las técnicas de ingeniería genética para un perfeccionamiento de nuestra especie remitimos a JUENGST E.; MOSELEY D.; "Human enhancement" en Stanford Encyclopedia of Philosophy https://plato.stanford.edu/archives/sum2019/entries/enhancement/ consultado el 18 de noviembre 2019.

${ }^{5}$ Sobre esta cuestión, véase ZUBOFF, S.; The age of surveillance capitalism: the fight for a human future at the new frontier of power, New York, Public Affairs 2019.
}

${ }^{6}$ HARARI, Y N; Homo deus: breve historia del mañana; traducción de Joan Domènec Ros, Barcelona: Debate, 2016 , p.382. 
Se puede afirmar que mientras hasta aproximadamente los años 70 las amenazas a la raza humana derivaban de los riesgos de la destrucción nuclear o ecológica, ahora se añaden dos nuevos desafíos, derivados de dos exigencias que siempre se han presentado a cada individuo como son la de mejorar su calidad de vida y la de tener el mayor acceso posible a la información y al conocimiento. En la actualidad las amenazas ya no se centran en la destrucción de la vida, sino en la modificación del ser humano como un ser con una identidad biológica determinada que comparte con todos los miembros de la misma especie. Por lo tanto, el riesgo catastrófico en estos momentos no sería únicamente la destrucción del medioambiente, sino también el nacimiento de una nueva especie de superhombre dotado con la capacidad de oprimir a todos los demás 7 .

Braidotti, contrariamente a Harari, presenta el término posthumano no como una amenaza para los valores que ella misma reconoce como vinculantes, a pesar de no considerarse una humanista liberal, sino como una nueva frontera para los movimientos sociales que critican el presente y sus instituciones y pretenden el reconocimiento de nuevas subjetividades.

Al comienzo del libro Lo Posthumano la autora clarifica el significado del término posthumano:

"nosotros afirmamos nuestro apego a la especie como si fuera un dato de hecho, un presupuesto. Hasta el punto de construir en torno a lo humano la noción fundamental de Derecho. Pero, ¿las cosas son de verdad así? Mientras hoy cada vez a menudo, las fuerzas sociales conservadoras y religiosas se afanan por reinscribir lo humano en lo interior de los paradigmas de la ley natural, el concepto mismo de humano ha explotado bajo la doble presión de los actuales progresos científicos y de los intereses de la economía global",

Los progresos científicos y tecnológicos nos demuestran que el hombre es la medida de todas las cosas, dueño absoluto de lo creado y vive una vida separada del resto de criaturas. Se reconoce, también por parte de las ciencias biológicas y neurológicas, el continuum entre la naturaleza humana

\footnotetext{
${ }^{7}$ Resulta interesante resaltar como los partidarios de la intervención genética para potenciar las cualidades humanas apelan a la "libertad morfológica, al derecho a modificar y mejorar el cuerpo, su cognición, sus emociones" y consideran prioritario defender el bienestar de todas las inteligencias, naturales y artificiales. Véase par. 7 y 8 de la Declaración Transhumanista disponible en BOSTROM, N.; "Una historia del pensamiento transhumanista", en Argumentos de Razón Técnica, $\mathrm{n}^{\mathrm{o}}$ 14, 2011, pp. 186-187, en URL https://institucional.us.es/revistas/argumentos/14/art_7.pdf

${ }^{8}$ BRAIDOTTI, R.; Lo Posthumano; traducción, Juan Carlos Gentile Vitale, Barcelona, Gedisa, 2015, p. 11.
} 
(bios) y la naturaleza no humana (zoe), en cuanto se trata de naturalezas vivas (se observa claramente la influencia de Spinoza y su rechazo al dualismo cuerpo-mente, naturaleza-divinidad).

"Desde mi punto de vista, el común denominador de la condición posthumana es la hipótesis según la cual la estructura de la materia viva es, en si vital, capaz de autoorganización y, al mismo tiempo, no naturalista. Este continuum naturaleza cultura es el punto de partida para mi viaje a la teoría posthumana", .

Precisamente Braidotti afirma, haciendo hincapié en el análisis de U. Beck ${ }^{10}$, que nos encontramos ante una transformación histórica en la que el hombre es capaz de modificar por completo el ámbito de la naturaleza, en cuanto que el ser humano puede determinar también el ámbito biológico y el medio ambiente en su conjunto. Citando una vez más a Harari, se podría afirmar que hemos pasado de ser una especie animal con particulares capacidades cooperativas y cognitivas, el homo sapiens, a ser un ser "divino", un "homo deus". Las posibilidades de la ingeniería genética, con la creación de organismos genéticamente modificados o también clonados, como la famosa oveja Dolly o las gemelas editadas genéticamente en China ${ }^{11,}$ y la destrucción ambiental han dado origen a una nueva edad de la tierra, bautizada como el antropoceno.

A este propósito la autora aclara que si entramos en una nueva época en la que el hombre tiene a su disposición medios técnicos que:

a) no se limitan a destruir la vida, como en la era atómica, sino que son capaces también de reconstruirla a nivel biológico y de crearla sobre la base de las exigencias del mercado,

b) modifican la relación del hombre con el ambiente, a través también de la tecnología genética, poniendo de manifiesto como nuestra identidad tiene una continuidad con la de los animales,

entonces precisaremos necesariamente también de una responsabilidad "posthumana".

\footnotetext{
${ }^{9}$ BRAIDOTTI, R.; Lo Posthumano, cit, p. 12.

${ }^{10}$ BRAIDOTTI, R.; Lo Posthumano, cit, p. 78.

${ }^{11}$ VIDAL LIY, M; “Científicos chinos aseguran haber creado los primeros bebés modificados genéticamente” El País 26 de noviembre de 2018. Disponible en el siguiente enlace https://elpais.com/elpais/2018/11/26/ciencia/1543224768_174686.html (última fecha de consulta 8 de mayo de 2019).
} 
“Este sentido de responsabilidad [del intelectual] expresa (...) un hábito del pensamiento que es grato a mi corazón y a mi mente, puesto que pertenezco a aquella generación que tenía un sueño. Éste era y es aún el sueño de constituir comunidades de aprendizaje reales: escuelas, universidades, libros, revistas y periódicos, currículos, debates, teatros, televisión, radio y programas multimedia- y más tarde sitios de internet y network on line- que se parecen a la sociedad que representan, sirven y ayudan a desarrollar. Es el sueño de la creación de un saber importante desde el punto de vista social, en sintonía con los principios fundamentales de la justicia social, el respeto a la dignidad humana y la diversidad, el rechazo del falso universalismo; el sueño de la afirmación de la positividad de las diferencias, los principios de la libertad académica, el antirracismo, la apertura al otro y la cooperación. A pesar de que yo sea propensa a un cierto anti-humanismo, no tengo ninguna dificultad de admitir que estos ideales son perfectamente compatibles con la filosofía de valores humanistas "12.

Pero, dentro de la amplia oferta de posiciones filosóficas que se autodefinen como posthumanas ¿en qué lugar podríamos situar las tesis de Braidotti? ¿Existe una diferencia entre "la condición posthumana" y la condición "transhumana"?

La pregunta no es baladí en cuanto que en el extenso debate que provoca la justificación moral de la utilización de las técnicas de ingeniería genética, para mejorar las capacidades humanas, o el empleo de las nuevas tecnologías frecuentemente se confunde el concepto de "posthumano" y el de "transhumano"13 incluso por sus propios protagonistas.

Según Llano Alonso podemos encontrarnos con al menos tres formas diferentes de entender el término transhumano:

como un transhumanismo en sentido cultural inspirado en autores como Deleuze, Foucault y Derrida en el que se crítica el proyecto universal de la ilustración occidental;

\footnotetext{
12 BRAIDOTTI, R.; Lo Posthumano, cit, p. 22.

${ }^{13}$ Así a modo de ejemplo el exponente más conocido de las teorías transhumanista, N. BOSTROM, emplea el término post-humano como un sinónimo de transhumano en "Why I want to be a posthuman when I grow up", en M. More y N. Vita More The Transhumanist reader: Classical and contemporary essays on the science, technology adn philosophy of the human future, Chichester, John Wiley \& Sons, pp. 28-53. En cambio, Hall, M.; The Bioethics of Enhancement, Transhumanism, Disability, and Biopolitics, Lexington Books, London, 2017, p. 12, cuando critica a Bostrom y realiza un especial hincapié en Foucault, considera que el posthumanismo es una version materialista del transhumanismo que rechaza el planteamiento de Bostrom: "Bostrom's vision of the posthuman is a realization of the fantasies of disembodiment and autonomy and so supports, rather than questions, normative subjectivity".
} 
como un transhumanismo en sentido biológico, en el que se "reivindica el ideal ilustrado de la perfectibilidad potencialmente infinita del ser humano";

como un transhumanismo en sentido cibernético, en el que se "pretende crear una nueva especie a partir de la hibridación hombre/maquina"14.

Sin embargo, esta clasificación de Llano Alonso no enfatiza en las diferencias de planteamiento entre los tres sentidos en relación con la superación del concepto de hombre en el momento histórico actual. Estos planteamientos no solo hacen un especial hincapié en doctrinas contrapuesta como, por una parte, las de los autores críticos de la ilustración como serían Foucault, Derrida o Deleuze y, por otra, autores como Rousseau y Condorcet, sino que conciben de una forma totalmente opuesta la relación que existe entre la persona y su cuerpo. De esta forma la propia Braidotti reconoce la existencia de varias propuestas que pretenden superar el humanismo de la ilustración, pero rechaza algunas de ellas. En especial las propuestas relativas al tercer sentido, anteriormente mencionado, al considerarlas como una forma de "fantasía transhumanista de abandonar la materialidad finita del ego encarnado" 15 .

Por lo tanto, consideramos más acertada la propuesta teórica de quien distingue entre transhumanismo y posthumanismo de la siguiente forma:

"[I]n posthumanism the concept serves as a label for a new narrative, which may replace that of 'the human', rather than one for a radically enhanced human being. Transhumanism, on the other hand, is characterized by a straightforward affirmation of technological augmentations and visions of an enhanced posthumanity" 16.

El filósofo del derecho debería tener en consideración los instrumentos teóricos que nos ofrece Braidotti, pues nos proporciona interesantes enfoques, aunque no del todo originales, para el análisis

\footnotetext{
${ }^{14}$ LlANO ALONSO, F. H.; Homo excelsior. Los límites ético-jurídicos del transhumanismo, Tirant Lo Blanc, Valencia 2018, pp. $28-29$. Este mismo autor emplea como sinónimos los dos términos en su monografía p. 68, 103, 117. En relación con el transhumanismo existe también una amplia bibliografía en castellano. Por ejemplo, DIÉGUEZ, A; Transhumanismo. La búsqueda tecnológica del mejoramiento humano, Herder, Barcelona, 2017, pp. 42-43 que diferencia entre el transhumanismo cultural o crítico (denominado, citando a Braidotti, "posthumanismo") y el transhumanismo tecnocientífico.

15 BRAIDOTTI, R.; Lo Posthumano, cit p. 110.

16 RANISCH R.; SORGNER, L, "Introducing Post- and Transhumanism”, en RANISCH R.; SORGNER, L. (eds.) Post- and Transhumanism. An Introduction, Frankfurt am Main, Peter Lange, 2014, pp. 8-9, pp. 8-9.
} 
jurídico de fenómenos como la reivindicación del reconocimiento de la identidad de género o de situaciones de vulnerabilidad interseccional (por ejemplo, el ser no sólo mujer sino también miembro de una minoría cultural en cuyo ámbito mantiene relaciones discriminatorias). Asimismo, resulta atrayente su elaboración del concepto de identidades nómadas que desarrolla a partir de su experiencia como emigrante; en un primer momento, junto a su familia desde Italia hasta Australia; después como estudiante de doctorado desde Australia hasta París; y, finalmente, en la actualidad como profesora en Holanda $^{17}$.Unas identidades nómadas que son siempre el resultado de un conflicto entre las tendencias hacia la uniformidad (también mediante la utilización de instituciones jurídicas, como la presunción de la igualdad en la libertad contractual, que conciben a los sujetos jurídicos como entes autónomos y con iguales oportunidades para lograr sus deseos, cuando en la realidad nos encontramos siempre con sujetos más fuertes y menos fuertes) y las resistencias por parte de los grupos minoritarios o más vulnerables que rechazan la validez y vigencia de dichas categorías. Coherentemente con la deuda contraída hacia sus maestros, Foucault y Deleuze, la autora nos presenta sendos argumentos en contra de la encrucijada aparente entre, por una parte, el relativismo o el escepticismo ético y, por otra parte, la aceptación acrítica del universalismo liberal y kantiano. El pensamiento feminista ha denunciado que “el matiz de género que ha teñido las nociones de razón, de objetividad y de lo universal mismo, siempre con una tendencia favorable a lo masculino". Braidotti, como otras feministas que hacen hincapié en Foucault o Deleuze, considera que la ética debe interesarse más "por la afectividad y las pasiones humanas entendidas como el motor de la subjetividad" ${ }^{18}$. Por lo tanto, no es necesario si dejamos atrás el universalismo liberal o kantiano, abandonar todo intento de criticar el mundo existente o de presentar concepciones alternativas de la persona, en particular de la que quiere escapar de las categorías que se presentan como "naturales", mientras que, como nos enseña Foucault, son el producto de concretas relaciones de poder que, como todo fenómeno humano, tienen un inicio y pueden tener un fin ${ }^{19}$.

\footnotetext{
${ }^{17}$ Muy sugerente resulta su introducción a su obra BRAIDOTTI R.; Sujetos nómadas, trad. castellana de A. Bixio, Paidós, Barcelona, 2000, pp. 13-23.

${ }^{18}$ BRAIDOTTI, Transposiciones, cit. p. 30.

19 "La elección de una figura iconoclasta, mítica, como la del sujeto nómada, sería la consecuencia de un movimiento en contra de la naturaleza establecida y convencional del pensamiento teórico, y especialmente, del filosófico. Esta figuración traduce, por lo tanto, mi deseo de indagar y legitimar la acción política, tomando al mismo tiempo como prueba histórica la decadencia de las identidades estables, metafísicamente fijadas”. BRAIDOTTI, Sujetos nómadas, cit. p. 31.
} 
El concepto de identidad nómada constituye un desafío para los estudios jurídicos, en especial para la sociología del derecho. Los estudios de Braidotti nos recuerdan la enorme distancia, que a menudo existe, entre la proclamación de la universalidad de los derechos y su ejercicio real. Así ocurre, por ejemplo, en el ejercicio de derechos como el de asociación, el de no discriminación o en el de la educación, etc. por parte de los sujetos que, bien por elección, por condiciones de pobreza, por falta de poder, por género o por cultura, se quedan al margen de estos, aunque sean numéricamente una mayoría $^{20}$. Y esta marginalidad se materializa en prácticas sociales, en normas, en costumbres consideradas no sólo legitimas sino también como "naturales" aunque resulten contradictorias con otras exigencias (basta pensar en los roles simultáneos que se esperan de la mujer, trabajadora, madre, compañera, hija, cuidadora, etc, en la sociedad actual).

Asimismo, compartimos la crítica que Braidotti realiza del papel conservador que algunas de las tradiciones del derecho natural atribuyen al término o la condición de "dignidad" y al "derecho a la vida" de los embriones, de tal forma que cuestionan o limitan la libertad de procreación de las mujeres y el control sobre su cuerpo. $\mathrm{O}$ a aquellas posturas que niegan la posibilidad de poner fin dignamente a la propia existencia ${ }^{21}$.

Pero en relación con tres cuestiones consideramos que el análisis del filósofo del derecho puede mostrar algunos de los problemas que plantea la teoría posthumana propuesta por Braidotti:

a) cómo tutelar el medioambiente sin incluir la idea de reconocer derechos a los animales o al menos una forma de obligación legal de cuidar su bienestar;

b) cómo tener en cuenta los fenómenos de control masivo de personas a través de la vigilancia electrónica que se desarrollan en los regímenes que no son de capitalismo privado o no occidentales (como por ejemplo China);

\footnotetext{
${ }^{20}$ Véase sobre esta cuestión a modo de introducción FRANCIS, L., SMITH, P., Feminist theory of law, en Stanford Encyclopedia of Philosophy, 2017 URL https://plato.stanford.edu/archives/win2017/entries/feminism-law/ (última consulta el 10 de mayo de 2019).

${ }^{21}$ A este respecto se pueden mencionar los recientes casos de la muerte de María José Carrasco en España, la polémica en Francia por el caso Vicent Lambert y la surgida en Holanda por la solicitud de eutanasia de la joven Noa de 17 años por el estrés postraumático, depresión y anorexia que padecía tras varias violaciones.
} 
c) cómo valorar los casos de modificación de la identidad sexual que tienen lugar antes de alcanzar la madurez de los órganos reproductivos mediante la utilización de fármacos que retrasan el proceso de pubertad.

En estos tres supuestos mostraremos como el derecho es necesario también en la era posthumana mencionada por Braidotti y cómo la falta de reconocimiento del papel del derecho tiene graves consecuencias en la plausibilidad de su planteamiento y en la distinción de planteamientos "transhumanistas" que la autora rechaza.

A este respecto traemos a colación el inicio del libro Lo Posthumano que reza así: el Derecho codifica la imagen humana, pero no la posthumana del sujeto ${ }^{22}$. Además, la referencia al Derecho natural parece que reduce el Derecho a un simple instrumento de justificación de las relaciones de poder existentes, convirtiéndolas en "esencias naturales" y, por lo tanto, en necesarias e inmutables.

Dicha impresión negativa de Braidotti hacia el derecho se refuerza con su propuesta de reforma de visión de los currículos en las facultades humanísticas y en general en las ciencias humanas. Dentro del elenco de disciplinas que propone introducir en dichos currículos para las ciencias humanas podemos encontrar: "informática humanística o digital, ciencias humanas neuronales y cognitivas, ciencias humanísticas ecológicas y medioambientales, ciencias humanas biogenéticas y globales”. En resumen, parece que el derecho no encuentra espacio en el bagaje cultural para el estudio de lo posthumano.

Sin embargo, consideramos que la perspectiva del filósofo del derecho puede ser útil y también necesaria para Braidotti. El filósofo del derecho y sobre todo el sociólogo del derecho estudia el fenómeno de la regulación de la sociedad a través de las normas (y entre estas los derechos) que se aplican a través de sanciones provenientes de los órganos públicos o por normas que atribuyen la facultad de producir otras normas (como los contratos, el testamento, el matrimonio, o el poder de constituir personas jurídicas como las asociaciones, las fundaciones, las cooperativas o las organizaciones sin ánimo de lucro, etc.) cuya violación puede ser sancionada por los órganos públicos. Además, el derecho es un ordenamiento de normas producido por autoridades humanas, y no divinas, que pretende, al menos actualmente, que se encuentren limitados por un conjunto de derechos fundamentales (los derechos humanos) y por un principio de separación de poderes, de tal forma que el

${ }^{22}$ BRAIDOTTI, R; Lo Posthumano, cit, p. 11. 
poder judicial puede declarar no aplicables aquellas disposiciones o procedimientos administrativos que violan la ley o las leyes que violan las Constituciones. Podemos afirmar que hoy en día casi todas nuestras acciones son objeto de regulación jurídica. Por lo tanto, consideramos que la perspectiva del filósofo del derecho puede ser de inestimable ayuda para el proyecto de ciencias humanas posthumanísticas y un saber crítico a la altura de los desafíos que es necesario afrontar. Un saber posthumano, que no sea éticamente neutral, tal y como parece proponer Braidotti, quien como hemos indicado intenta tutelar en las prácticas de construcción de las identidades algunos valores humanistas, como la determinación autónoma de nuestras identidades y la responsabilidad hacia el resto de las especies existentes.

La propia Braidotti reconoce la importancia de los derechos humanos en su filosofía.

“Inyectaré el feminismo, el antirracismo y las cuestiones ambientales y de derechos humanos como impulsores adicionales de energía teórica" ${ }^{23}$.

Por otra parte, la autora afirma que su teoría va más allá de la "lógica de los derechos".

"La ética posestructuralista se interesa por la afectividad y las pasiones humanas entendidas como el motor de la subjetividad y no tanto por el contenido moral de la intencionalidad, la acción, o la conducta o la lógica de los derechos ${ }^{24}$.

Sin embargo, tal y como explicaremos, presenta una carencia de atención al derecho y a la manera en que el mismo implementa las relaciones a través de normas que imponen una serie de derechos y obligaciones que producen unos resultados extremadamente relevantes para la doctrina de Braidotti que:

1) reduce la relación entre el hombre y el animal a una mera relación de afectividad, de tal forma que se idealiza la noción de la responsabilidad de los seres humanos para con los seres nohumanos;

\footnotetext{
${ }^{23}$ BRAIDOTTI, R.; Transposiciones: sobre la ética nómada; traducción de Alcira Bixio, Barcelona, Gedisa, 2009 , p. 23.

${ }^{24}$ BRAIDOTTI, R.; Transposiciones: sobre la ética nómada; cit, p. 30.
} 
2) pierde de vista la necesaria relación entre las formas de producción, en particular de las diversas versiones del capitalismo, y el derecho; de este modo no se percibe como los riesgos de "mercantilizar" la naturaleza o de poner bajo control a las personas son más acuciantes en países como China que no tienen un Estado de Derecho,

3) corre el riesgo de justificar en nombre de la "libertad de construir la propia identidad sexual" un sometimiento a las lógicas del mercado.

\section{La relación entre el hombre y el animal. El derecho y la responsabilidad del hombre en} relación con el mundo viviente.

En primer lugar, consideramos que el estudio de la Filosofía del Derecho, en relación con los derechos de los animales, puede serle útil a Braidotti para definir de qué modo tutelar a los animales respecto a la amenaza de la mercantilización de los genes a manos de un capitalismo que se apropia no sólo de los cuerpos sino también de los genes. Es oportuno ceder una vez más la palabra a la autora para tratar esta cuestión.

"El capitalismo avanzado, al mismo tiempo, invierte y obtiene provecho del control cientifico o económico sobre la mercantilización de todo lo vivo. Este contexto genera una forma paradójica y más bien oportunista de postantropocentrismo en beneficio de las fuerzas de mercado que impunemente privatizan la vida misma” 25

Braidotti se refiere a los procesos de modificación a través de la ingeniería genética de las especies. Unos unos procesos que permiten al hombre, considerado como dueño de los seres vivos y manipulador del medioambiente, afirmar su dominio sobre la naturaleza y, por lo tanto, como algo que puede separarse de ella según sus deseos. Además, este control se codifica en normas que reconocen los derechos de propiedad sobre los organismos genéticamente modificados. Los análisis de Braidotti, que se basan esencialmente en la advertencia de autoras como Vandhana Shiva, desafortunadamente parecen confirmarse. Ahora, tal y como afirma Llano Alonso, parece que incluso las relaciones educativas entre los padres y los hijos o entre el profesor y el discípulo deben regirse según los imperativos de la eficiencia de aprender nociones y sobre todo en técnicas que se puedan ofertar en el

${ }^{25}$ BRAIDOTTI, R.; Transposiciones; cit, p. 76. 
mercado laboral. En este sentido se podría justificar también la utilización de la manipulación genética para producir una nueva humanidad que pueda controlar y enfrentarse a unos bots que podrían superar rápidamente las capacidades humanas ${ }^{26}$.

Sin embargo, es posible realizar una lectura posthumana no capitalista de la continuidad entre la vida humana y la vida animal.

"la vida, en vez de ser definida como propiedad exclusiva y derecho inalienable de una sola especie, la humana, sobre todas la demás, en vez de ser santificada como una tesis predeterminada, es entendida como un proceso interactivo y sin conclusiones. Esta aproximación vitalista a la materia elimina los confines binarios entre aquella parte de vida, sea orgánica, sea discursiva, tradicionalmente reservada al anthropos, es decir, el bios, y la parte más amplia de la vida animal y no-humana, también conocida como zoe. Zoe como fuerza dinámica de la vida en sí capaz de autoorganización, permite la vitalidad generativa. (...) el igualitarismo zoe-centrado es, para mí, el núcleo de la inflexión postantropocéntrica: es una respuesta materialista, laica, fundada y concreta a la oportunista mercantilización transespecie que es la lógica del capitalismo avanzado. ”27

En Transposiciones afirma Braidotti citando a D. Haraway ${ }^{28}$ :

"Haraway sostiene que las divisiones sujeto-objeto-naturaleza-cultura están vinculadas con lo patriarcal, es decir, con las narrativas familiares edípicas. Contra ellas recomienda un sentido ampliado de la comunidad basado en la empatía, la responsabilidad y el reconocimiento. Además extiende estas prerrogativas a los agentes o sujetos no humanos, como los animales, las plantas, las células, las bacterias y la tierra en su conjunto”.

Esta continuidad entre el hombre y la naturaleza (no humana) lleva a Braidotti a manifestar una cierta sospecha ante las diferentes propuestas que atribuyen a los animales algunos derechos, en especial el de no interferencia, característicos de la especie humana, atribuyendo a estos una dignidad que antes de la edad posthumana solo se reconocía a los seres humanos. Se trataría solo de un

\footnotetext{
${ }^{26}$ Véase LLANO ALONSO, cit., pp. 109 ss.

${ }^{27}$ BRAIDOTTI, R.; Transposiciones, cit, p. 77.

${ }^{28}$ BRAIDOTTI, R.; Transposiciones, cit, p. 88.
} 
neohumanismo postantropocéntrico, no de un verdadero y propio posthumanismo. De tal forma que, mientras el neohumanismo postantropocéntrico transfiere a los animales, o al menos a los primates, las cualidades del sujeto humano considerado como un hombre, blanco, propietario, autónomo y racional-, el posthumanismo negaría dichas cualidades, haciendo posible una identificación entre el hombre y el animal.

“(...) la razón por la que soy, de algún modo, escéptica en relación al neo-humanismo postantropocéntrico (...) consiste en el hecho de que éste no es crítico respecto del humanismo en sí. Los esfuerzos compensadores por cuenta de los animales generan la que yo considero una especie de tardía solidaridad entre los habitantes humanos del planeta, actualmente traumatizados por la globalización, la tecnología y las nuevas guerras, y los correspondientes otros animales. Éste es, a lo sumo, un fenómeno ambivalente, desde el momento que combina un sentimiento negativo de vínculo entre las especies con un clásico y bastante magnánimo acento moral humanista. (...)’”

Antropomorfizar en modo de extender a los animales el principio de igualdad moral y jurídica puede ser un gesto noble, pero es intrínsecamente defectuoso, al menos por dos motivos. En primer lugar, ésta confirma el sistema binario de distinción entre hombre y animal, imponiendo, aunque sea con un buen fin, la categoría hegemónica de los humanos a los otros. En segundo lugar, niega completamente las especificidades de los animales, porque los trata de manera uniforme, como símbolos del valor transespecie, a través del mismo y universal sentimiento de empatía." 29

Así concluye Braidotti señalando que el reconocimiento de la dignidad de los animales depende de la participación, que es propia de las mujeres, de una situación común de explotación.

"Mi posición situada de hembra de la especie me hace estructuralmente más cercana a los organismos vivos de los que extraemos órganos y células sin su consentimiento, que a cualquier noción abstracta de inviolabilidad y de integridad de la especie humana” ${ }^{30}$.

De este modo, mientras resultan claras las premisas metodológicas y metafísicas de la tesis de Braidotti, no serían tan evidentes sus conclusiones prácticas, en cuanto que la cuestión ecológica parece

\footnotetext{
${ }^{29}$ BRAIDOTTI, R.; Transposiciones, cit, pp. 96-97.

${ }^{30}$ BRAIDOTTI, R.; Transposiciones; cit, p. 98.
} 
reducirse a un problema de repensar por parte del hombre su posición de encontrase situado en un planeta y, por tanto, una especie de retorno a las tesis de Hegel sobre la primacía del espíritu sobre la materia $^{31}$.

Podrían ayudarle en este último aspecto, algunas de las reflexiones sobre los derechos de los animales elaboradas por la Teoría del Derecho. Al respecto, Francesco Viola ${ }^{32}$ reconstruye como los ordenamientos jurídicos tutelan ya hoy bienes no humanos, como la tutela del medioambiente o el bienestar de los animales, pero sin atribuirles una subjetividad jurídica (a saber: la capacidad de producir actos jurídicos) y derechos. El ser hombre, en los ordenamientos que tutelan dichos bienes jurídicos, no implica por lo tanto el antropocentrismo, ni reduce el medioambiente o al animal a un simple instrumento, sino que reconoce en el hombre un titular de derechos, pero también un titular de deberes de cuidado en relación con los seres vivos. Al mismo tiempo, Viola sostiene que el ser humano es titular de derechos frente a los otros miembros de la especie humana y solo frente a ellos ${ }^{33}$. Por ejemplo, que tiene el derecho de que no le robe otro ser humano, o que no le mate otra persona, pero no tiene los mismos derechos frente a un animal, puesto que no puede, en caso de incumplimiento, denunciar al animal ante un tribunal ${ }^{34}$. Incluso en los supuestos relacionados con los derechos de autor, un animal no podría reclamarlos judicialmente ${ }^{35}$. Una posición desde la cual también se recuerda que el hombre tiene una serie deberes para con los animales. Deberes que se han ampliado con el tiempo, hasta el extremo que actualmente encontramos nuevas prohibiciones relacionadas con cuestiones como el bienestar animal como serían las limitaciones a la crianza intensiva, que se fundamentarían no en la

\footnotetext{
${ }^{31}$ Afirma Braidotti: "Una vía más igualitaria, zoe-centrada, requiere una pizca de buena voluntad por parte del sujeto dominante, en este caso el anthropos mismo, hacia los otros no humanos. (...) El alejamiento postantropocentrico de las relaciones jerárquicas que privilegiaban al Hombre exige al sujeto una especie de extrañamiento y de reposicionamiento radicales. La mejor manera de asumir esta tarea es la estrategia de la desfamiliarización o de la toma de distancia crítica de la visión dominante del sujeto. (...) Un sujeto posthumano asi constituido excede tanto los confines del antropocentrismo como del humanismo compensatorio, para adquirir una dimensión planetaria" BRAIDOTTI, R.; Lo Posthumano, cit, p. 107.

32 VIOLA, F., De la naturaleza a los derechos: los lugares de la ética contemporánea (1996) trad. del italiano y estudio introductorio a cargo de Vicente Bellver, Granada: Comares, 1998, cap. IV e cap. V par. 8.

${ }^{33}$ En nuestro país comparten esas tesis autores como Cortina, A; "La pequeña simia", El País, 5 de septiembre de 2016. Disponible en el siguiente enlace https://elpais.com/diario/2006/09/05/opinion/1157407205_850215.html (última fecha de consulta 9 de junio de 2019) o Talavera, P. "De humanos y de simios: la genética y los derechos", Revista de Bioética y Ciencias de la Salud, vol. 2 (2009), pp.4-16.

${ }^{34}$ Hay que aclarar que al menos en la primera edad moderna hay constancia de juicios en contra de animales. Véase CASTRO ÁlVAREZ, C.; Los animales y su estatuto jurídico. Protección y utilización de los animales en el derecho, Aranzadi, Cizur Menor, 2019, p. 37-39.

${ }^{35}$ La larga batalla legal por el "selfie" del mono termina con una victoria para el ser humano, BBC.com, 12 de septiembre de 2017, disponible en el siguiente enlace: https:/www.bbc.com/mundo/noticias-41238032 (última consulta 6 de mayo de 2019).
} 
atribución de una serie de derechos a los animales, sino en el valor moral intrínseco de los mismos que no pueden reducirse a una analogía con el ser humano.

Un planteamiento que libera el debate entre las distintas tesis que defienden lo que la propia Braidotti considera como una forma de humanismo resarcitorio. En concreto nos referimos al utilitarismo de Singer que atribuye derechos a los animales sobre la base de su percepción del dolor, y nosotros añadimos, también Regan, que atribuye derechos tanto a los hombres como a los mamíferos en la medida en que tengan una conciencia de sí mismos ${ }^{36}$. De esta forma Braidotti considera que "la posición utilitaria de Singer consiste en antropomorfizar a los animales, extendiendo a ellos el principio de igualdad o de derechos igualitarios y que su postura filosófica es el devenir humano de los animales $" 37$.

En consecuencia, las posiciones, como las de Singer, tienen el problema de: a) permanecer en todo caso empantanadas en un especismo antropológico ${ }^{38}$; b) considerar menos que humanos y, por lo tanto, sin derechos a los individuos que padecen enfermedades incapacitantes. A tal propósito la progresiva extensión de los instrumentos de tutela jurídica en relación con el medioambiente o la prohibición de una serie de tratos que causan sufrimiento a los animales - a menudo justificados por razones religiosas-, que imponen una serie de normas para el sacrificio ritual de los animales ${ }^{39}$ es una demostración de la circunstancia de que las prácticas jurídicas pueden convertirse en un remedio para los asuntos relativos a la responsabilidad humana en relación con el planeta. Aspectos que determinan la condición posthumana hoy en día. En nuestra opinión se trataría además de una solución ciertamente

\footnotetext{
36 Autores como Singer, P.; Liberación animal, Taurus, Madrid, 2011, Kymlicka, W y Donaldson, S.; Zoópolis, Una revolución animalista, Errata Naturae, Madrid, 2018 o Pelluchon, C; Manifiesto animalista, Politizar la causa animal, Reservoir Books, Barcelona, 2018 defienden otro tipo de posiciones más extremas que van desde el reconocimiento de derechos hasta la reformulación del concepto de ciudadanía o la política.

${ }^{37}$ BRAIDOTTI, R., Transposiciones: sobre la ética nómada; cit, p. 135.

${ }^{38}$ VIOLA, F., De la naturaleza a los derechos: los lugares de la ética contemporánea, cit, cap. VI.

${ }^{39}$ Así una reciente sentencia del Tribunal de Justicia de la Unión Europea (Gran Sala) del 26 de febrero de 2019 en el asunto C-497/17 en la que se establece que la carne de animales sacrificados sin aturdimiento, en este caso siguiendo el rito halal, no puede llevar el logotipo europeo de producción ecológica porque no respeta las normas más exigentes sobre bienestar animal. (par. 52).
} 
más realista ${ }^{40}$ que el hipotético diálogo imaginario con los animales no humanos que parece que imagina Braidotti cuando afirma:

“Deseo pensar a partir del aquí y ahora, de mi hermana Dolly, la oveja (...). Interpreto la inflexión posthumana como una feliz oportunidad de decidir juntos qué y en quién nos podemos convertir, una posibilidad única para la humanidad de reinventarse en sentido afirmativo" ${ }^{41}$.

Es más, sostener que basta imaginar, o reconocer, una cierta identidad al ser humano en nuestra era antropocéntrica análoga a la comprensión de la mujer como sujeto que sufre dominación, nos parece que conduce el debate sobre la responsabilidad del ser humano en relación con el medioambiente a las tesis de que basta una idea, una comprensión del ser humano, para modificar la realidad ${ }^{42}$. Una paradoja para una teoría, la de Braidotti, que considera al hombre como una unidad entre un espíritu y un cuerpo inseparable del medioambiente viviente.

\section{3. ¿Qué capitalismo? Algunas distinciones relevantes}

Los textos de Braidotti hacen referencia al capitalismo global visto como una fuerza que mercantiliza todas las relaciones entre los seres humanos, que convierte el patrimonio genético en un recurso manipulable para obtener provecho y que transforma las relaciones de dominación entre los sexos en relaciones igualitarias entre consumidores.

\footnotetext{
${ }^{40}$ En este sentido consideramos que se debería reivindicar la aplicación efectiva de la Declaración de Responsabilidades y Deberes de Valencia, UNESCO, 1998. En especial su artículo 9, en el que bajo el título "La obligación y la responsabilidad de proteger y promover un medio ambiente seguro, estable y sano", establece lo siguiente:

1. Los miembros de la comunidad mundial tienen obligaciones y responsabilidades colectivas, así como individuales, de respetar, proteger y preservar el carácter único y la diversidad de todas las formas de vida y preservar y promover un medio ambiente apropiado para el mantenimiento de todas las formas de vida.

2. Para ello: a) Los estados, los agentes no estatales pertinentes, incluyendo el sector privado y las personas tienen la obligación de proteger y preservar la estabilidad y la calidad del medio ambiente mundial, regional y local y de utilizar los recursos naturales, de forma que se consiga la preservación y protección de la biodiversidad-; b) Los estados, los agentes no estatales pertinentes, incluyendo el sector privado y las personas, tienen la obligación de conservar los recursos naturales e impedir la degradación y la destrucción del medio ambiente por el abuso, la explotación y el consumo excesivo-; c) Los estados, las organizaciones intergubernamentales y todos los agentes pertinentes no estatales, incluyendo el sector privado y las personas, tienen la obligación de preparar y promover un flujo libre de información científica básica en cuanto al medio ambiente y promoverán y facilitarán la investigación y el análisis necesarios para el desarrollo de nuevos métodos y modelos apropiados para la preservación y promoción de un medio ambiente seguro, estable y saludable.

${ }^{41}$ BRAIDOTTI, R.; Lo Posthumano, cit, p. 231.

42 Desconocemos cuál sería la posición de la autora en relación con el primer caso transespecie dado a conocer a la opinión pública recientemente, en el que un hombre británico de 32 años reclamó en el programa televisivo británico This Morning que se le recenezea reconociera como un cachorro de perro dálmata, El primer hombre 'transespecie' se reivindica en televisión, La Vanguardia, 5 de junio de 2019, disponible en el siguiente enlace https://www.lavanguardia.com/television/20190605/462698076310/perro-cachorro-dalmatahombre-transespecie-entrevista-television.html (última consulta 11 de junio de 2019).
} 
Así en Transposiciones la autora destaca la paradoja entre un arcaísmo remanente y un hipermodernismo característico de las épocas de cambios acelerados como los que experimentan hoy las sociedades avanzadas ${ }^{43}$.

Una contradicción que la autora refleja claramente en la esquizofrenia contemporánea que aqueja al capitalismo y al consumismo compulsivo de la cultura de masas que enfatiza una búsqueda de especificaciones o mercancías personalizadas y que produce un desastroso doble efecto al reafirmar el individualismo como la norma indiscutiblemente deseable a la vez que lo reduce únicamente a marcas y logotipos. Una situación que convierte el lema "voy de compras, luego existo"44 en el principio de nuestro tiempo, priorizando el beneficio comercial hasta los límites más íntimos de la subjetividad.

En este caso consideramos, adecuada la tesis de Braidotti, pero requiere de algunas precisiones que el filósofo del derecho puede formular.

¿Podemos hablar de una economía de mercado cómo una forma unívoca de producción y distribución de las mercancías? ¿O bien los sistemas jurídicos determinan las distintas formas de capitalismo que a su vez pueden tener consecuencias sobre los ideales éticos de Braidotti? En este caso sería conveniente recordar el tratamiento de cuestiones como la no discriminación, el desarrollo de las identidades irreductibles a las relaciones de dominación o a las lógicas del mercado, la tutela del medioambiente o la libertad académica, entre muchas otras.

Respecto a los riesgos que conlleva la implantación de un control de los individuos a través de la realización de investigaciones personalizadas del $\mathrm{ADN}$, que pueden determinar la probabilidad de padecer determinadas enfermedades o determinadas actitudes sociales, Harari sostiene que:

“Estos resultados contendrán una lista de los riesgos potenciales a la salud a los que el cliente se enfrenta, y su disposición genética para más de 90 rasgos y condiciones, que van desde la calvicie a la ceguera. «Conócete» no fue nunca tan fácil ni tan barato. Puesto que todo se basa en estadísticas, el tamaño de la base de datos de la compañía es la clave para hacer predicciones precisas. De ahí que la primera compañia que elabore una base de datos genéticos gigante proporcionará a sus clientes las

\footnotetext{
${ }^{43}$ BRAIDOTTI, R.; Transposiciones: sobre la ética nómada; cit, p. 18.

${ }^{44}$ BRAIDOTTI, R.; Transposiciones: sobre la ética nómada; cit, p. 17-18.
} 
mejores predicciones y podrá acaparar el mercado. Las compañias biotecnológicas estadounidenses están cada vez más preocupadas porque las estrictas leyes de Estados Unidos sobre privacidad sumadas al desprecio chino hacia la intimidad individual puedan servir en bandeja el mercado genético a China" ${ }^{45}$.

Por otra parte, el gobierno chino ha puesto en funcionamiento el sistema de medios de reconocimiento en masa más intensivo conocido al menos hasta el momento, con la elaboración de una base de datos en la que se introducen todas las imágenes obtenidas por las cámaras ubicadas en los espacios públicos y analizadas en potentes ordenadores que pueden reconstruir cada acto realizado por un ciudadano. Y todo ello sin pasar por ningún filtro o autorización judicial, sólo mediante una orden gubernamental.

En este caso, resulta superfluo afirmar que sin un conocimiento de los ordenamientos jurídicos la referencia al capitalismo como motor de la civilización posthumana tiene una consecuencia negativa. No se tiene en consideración que no todas las formas de capitalismo son iguales, algunas, como la vigente en países como China, están regidas por ordenamientos jurídicos en los que no existen derechos cuya tutela se pueda reclamar ante tribunales independientes del poder ejecutivo ni tampoco existe un catálogo de derechos fundamentales que limite las facultades del poder legislativo y ejecutivo.

Una alarmante situación que se describe de forma ilustrativa como el "gran hermano" chino en el siguiente artículo "Por un lado, los 180 millones de cámaras de vigilancia que hay instaladas en todo el país -20 millones de ellas, dotadas con inteligencia artificial-, que controlan todo lo que sucede y lo que hacen sus ciudadanos. Por otro, un férreo control sobre internet y las redes sociales, que les permite saber qué publica y qué ve cada uno de los internautas del país asiático ${ }^{46}$ ".

El resultado de este experimento sociológico es que se pueden conceder puntos a los ciudadanos y en caso de que se perciban actitudes poco ortodoxas a partir del 2020 las puntuaciones influirán en la capacidad para alquilar una vivienda, obtener un seguro o un préstamo e incluso en la obtención de beneficios en la sanidad pública. Los ciudadanos con puntuaciones bajas tampoco podrán ser

\footnotetext{
${ }^{45}$ HARARI, Y N; Homo deus: breve historia del mañana, cit, p.368.

46 MOLINA, A.; "China estrena su "Gran Hermano", La Vanguardia 3 de mayo 2018, https://www.lavanguardia.com/internacional/20180503/443196686690/china-puntuacion-ciudadanos-delitos-sociales.html, última consulta 9 de mayo.
} 
contratados para determinados empleos y tendrán incluso restringida la matrícula de sus hijos en escuelas privadas ${ }^{47}$.

En estos casos los espacios de resistencia y de construcción autónoma, de los sujetos de los cuales tanto habla Braidotti en su idea de identidades nómadas, son extremamente reducidos, por no decir irreales. Sin la existencia de un sistema de derechos, no hay formación autónoma de identidades, al menos en la realidad. ¡En nuestra mente o también en sueños naturalmente podemos creer que tenemos cualquier identidad...siempre que no nos atrevamos a decirlo!

\section{4. ¿Puedo elegir mi identidad sexual (si soy un menor)?}

Braidotti intenta modificar los términos en los que se plantea el debate feminista en relación con la diferenciación del género, al considerar la identidad sexual no como el resultado de un proceso de dominación de la cultura masculina sobre la identidad femenina, sino más bien como un proceso de construcción de una identidad "diferente" respecto a la identidad atribuida por parte de las instituciones culturales masculinas.

En Lo Posthumano ${ }^{48}$ la autora se plantea el problema de cómo las técnicas de ingeniería genética y la biotecnología han modificado el debate sobre la diferencia de género y las modalidades de construcción de la identidad sexual:

“Cuáles son las consecuencias del hecho de que el aparato tecnológico ya no sea sexualizado, naturalizado y racializado, sino más bien neutralizado como cifra de la mezcla, el hibridismo y la interconexión, en el momento en el que transexualidad deviene topos posthumano? Si la maquina es capaz de autogestión y es, al mismo tiempo, transexual, el viejo y orgánico cuerpo humano necesita ser colocado en otra parte ${ }^{49}$,

\footnotetext{
${ }^{47}$ MOLINA, A.; "China estrena su 'Gran Hermano"”, cit. Sobre el tema de las prácticas de control de la ciudadanía a través de internet en China, nos remitimos también a HOU, R; "Neoliberal governance or digitalized autocracy? The rising market for online opinión surveillance in China”. Surveillance \& Society, 2017 15(3/4),pp. 418-424, y más detenidamente a ZUBOFF, S.; cit., cap. 13.

${ }^{48}$ BRAIDOTTI, R.; Lo Posthumano, cit, p. 117.

49 JUÁREZ, B.; “Q, el primer asistente de voz asexual”, El País, 19 de marzo de 2019, disponible en https://elpais.com/tecnologia/2019/03/12/actualidad/1552393305_744375.html (última consulta 11 de junio de 2019).
} 
Recurrentemente la autora afirma ${ }^{50}$ :

"necesitamos revalorizar la potencia generativa del cuerpo de las mujeres. Desde esta perspectiva, el género es sólo un mecanismo histórico y contingente de la captura de las múltiples potencialidades del cuerpo, incluida sus capacidades generativas y reproductivas. Transformar el género en matriz transhistórica del poder, como sugiere la teoría querer de la tradición lingüística socioconstructiva (...) constituye simplemente un error conceptual y político. (...) Necesitamos experimentar con resistencia e intensidad con el fin de comprender qué pueden nuestros cuerpos posthumanos.

(...)

He afirmado que el feminismo vitalista, materialista y posthumano, apoyándose en una ontología política monista y dinámica, desplaza la atención lejos de la distinción sexo/género, poniendo en relieve la sexualidad como proceso. Esto significa, por extensión, que la sexualidad es una fuerza, un elemento constituyente, capaz de desterritorializar la identidad de género y sus instituciones. Unido a la idea del cuerpo como de un ensamblaje de posibilidades virtuales, esta aproximación postula la prioridad ontológica de la diferencia y su fuerza autotransformadora”.

¿Pero cómo podemos evitar el riesgo de que tales voluntades de transformación se conviertan una vez más en una forma de identidad con la que se pueda comerciar? De esta forma resulta notorio que se comercializan algunos productos como la triptorelina, cuya patente permite obtener importantes beneficios a la industria farmacéutica, que retrasan el proceso de madurez en los sujetos que son menores de edad, con la finalidad de reducir el estrés social, y en particular el acoso escolar, del que pueden ser objeto los menores que no se reconocen en su cuerpo, una alteración de la personalidad denominada disforia sexual ${ }^{51}$. Según una investigación llevada a cabo por la revista Lancet diabetes and endocrinology en $2017^{52}$ en una muestra de 218 menores se diagnosticaron: 84 casos de autolesión, 29 intentos de suicidio y 74 pensamientos suicidas. Por esta razón la AIFA, la Agencia Italiana del Fármaco, ha determinado la prescripción y el rembolso de este tipo de fármacos, en cuanto que retrasan

${ }^{50}$ BRAIDOTTI, R.; Lo Posthumano, cit, p.118-119.

${ }^{51}$ VALESINI, S.; "Triptorelina per la disforia di genere anche in Italia: non fa cambiare sesso e salva vite", en wired, 8 marzo 2018 , https://www.wired.it/scienza/medicina/2019/03/08/triptorelina-disforia-genere/?refresh_ce= 8 última consulta 9 de mayo 2019).

52 MAHFOUDA, S.,MOORE, J.K., SIAFARIKAS, A., ZEPF, F., D., LIN, A.; Lancet diabetes and endocrinology en 2017 (vol. 5 , issue 10), https://www.thelancet.com/journals/landia/article/PIIS2213-8587(17)30099-2/fulltext última consulta 10 de mayo 2019. 
los efectos somáticos de la pubertad y ofrecen a quien los toma más tiempo para decidir sobre su propia identidad sexual y por tanto para iniciar un tratamiento hormonal al que le seguiría una intervención quirúrgica $^{53}$.

En este caso Braidotti también podría encontrarse en apuros. ¿Nos hallamos frente a una utilización de la tecnología biomédica, o por el contrario asistimos a un caso de mercantilización de la identidad sexual, vista como algo que se puede adquirir, y no como un proceso? En este supuesto además se trata de menores y, por tanto, de sujetos especialmente vulnerables en cuanto que la unidad de cuerpo y mente de la que habla Braidotti todavía no está concluida.

Acerca del tema de la identidad sexual, parece que Braidotti confía en la dimensión colectiva de la identidad sexual.

"Una política materialista de las diferencias posthumanas se sirve de devenires potenciales que exigen su actualización. Éstos se concretan en praxis colectivas basadas en las comunidades, y se convierten en fundamentales para sostener el proceso vitalista de la recomposición no unitaria pero responsable de un pueblo faltante. Éste es el nosotros que es evocado y actualizado, por ejemplo, por la creación postantropocéntrica de una nueva panhumanidad ${ }^{54, "}$

Sin embargo, en nuestra opinión, resulta bastante confuso como el abrazo de una comunidad pueda resolver el problema ético y jurídico del carácter disponible y tutelado indirectamente por el Estado de la identidad sexual. Sobre todo, si nos referimos a menores. Al final se podría sostener que nada nos puede demostrar que también la comunidad de los transexuales no resulte al final una víctima más de una forma de "consumismo" de la identidad sexual. Si no es de esta forma es porque una comunidad de expertos reconoce una parte patológica en el proceso de construcción de la identidad de un individuo, la denominada disforia sexual. Un proceso que además tiene una importante componente espiritual (el malestar psíquico de vivir en un cuerpo que no se siente como el propio), mientras que se solicita a la técnica que retrase otro proceso, el biológico.

\footnotetext{
${ }^{53}$ Las elaboraciones teóricas y las tecnologías médicas en la construcción de la identidad "transexual" resultan un punto clave para las teorías feministas. Para una primera introducción véase BETTCHER, T.; Feminist Perspectives on Trans Issues (2014), URLhttp://plato.stanford.edu/archives/spr2014/entries/feminism-trans/ (última consulta 12 de mayo de 2019) especialmente pp. 29-38.

54 BRAIDOTTI, R.; Lo Posthumano, cit, p 120.
} 
Unas observaciones, que consideramos suficientes para cuestionar dos puntos fundamentales de la teoría Braidotti sobre el posthumano: la indisolubilidad del cuerpo y de la identidad; y el carácter resistente, no reducible a modelos de consumo o capitalistas, de la construcción de la subjetividad, individual y/o colectiva.

En nuestra opinión, una vez más el problema se podría resolver, o al menos atenuar, por el derecho. Como hemos afirmado al principio, hoy en día los ordenamientos, al menos aquellos occidentales, reconocen las pretensiones propias de cada sujeto, independientemente de las consecuencias que puedan producir en relación con los valores contrarios a cuestiones como la utilidad social, la seguridad colectiva, el poder del Estado etc. Respecto al caso de la disforia sexual, nos parece que un filósofo del derecho puede entender mejor como una estrategia del reconocimiento del derecho a la salud permite escapar del dilema de la identidad sexual medida por códigos de consumo o como un bien de identidad sexual inmodificable. Asimismo, puede reconocer también reconocer a los menores la posibilidad de retrasar mediante fármacos su proceso de madurez sexual, pero sólo si lo traducimos, a través del juicio de expertos reconocidos por el ordenamiento, en un derecho a la salud.

Sin estos procedimientos sanitarios justificados a través de un derecho a la salud, y no a un derecho a elegir su propia identidad corpórea, la teoría de Braidotti no nos serviría para resolver si las peticiones de cambio de sexo no sean de nuevo una forma de mercantilización del cuerpo, y no un proceso de construcción social de una identidad. Resulta evidente que Braidotti podría rebatir este argumento afirmando que su tesis no impone ninguna forma determinada para regular los procedimientos de cambios de sexo, sino que simplemente presenta un marco teórico y no normativo. Sin embargo, de esta forma nos quedaríamos otra vez con la sospecha de que sin un enfoque jurídico muchos de los argumentos que nos ofrece Braidotti sobre el tema de las técnicas biológicas de cambio de identidad sexual se reducen a un diálogo con escasas consecuencias prácticas sobre cómo regular estos fenómenos. O peor aún, corren el riesgo de justificar la reducción de su planteamiento posthumano a un transhumanismo que ve el cuerpo no como una parte de una identidad, sino como un instrumento que ha de ser mejorado constantemente, tal y como la sociedad exige, o para satisfacer nuestros deseos. 


\section{Conclusión}

Mi formación como jurista y como filósofa del derecho me ha encaminado hacia una visión más bien pragmática de la rica argumentación de Bradiotti. Seguramente sus libros son útiles para poner de relieve cuan insuficientes son nuestras ideas sobre la identidad personal y cuan frágiles son las categorías que nos sirven para actuar en un mundo en el que la técnica puede modificar, mercantilizar y destrozar la naturaleza. Es por ello que sus ideas de posthumano y de identidades nómadas, es decir en perpetua construcción colectiva, son necesarias. Sin embargo, he tratado de argumentar como las ideas de Braidotti necesitan de una profundización hacia la Filosofía del Derecho y sus categorías, al menos por tres razones:

a) Sin una distinción entre los derechos, que son propios sólo de los miembros de la raza humana, y los deberes (de la humanidad) hacia los animales y el medioambiente la aportación de Braidotti, en relación con los problemas de la ética medioambiental, se reduce a un rechazo hacia otras doctrinas, sin consecuencias prácticas sobre cómo debemos actuar en la edad del antropoceno (una edad geológica en la que la tierra se transforma a raíz de intervenciones humanas).

b) Sin una aclaración de la relación entre el capitalismo y el Estado de Derecho, la autora termina por no tener en cuenta las peligrosas consecuencias de las prácticas de vigilancia o de control genético puestas en marcha hoy en países capitalistas como China donde no hay un Estado de Derecho,

c) Sin una profundización de la cuestión del cambio de sexo como un problema de salud objeto de un derecho, y no como un simple deseo de modificar su cuerpo, se cae en la trampa de considerar el cuerpo como un objeto de consumo, una mercancía, con resultados alarmantes en el caso de peticiones de cambio de sexo cuando se trata de menores. 


\section{Referencias bibliográficas}

BETTCHER, T.; Feminist Perspectives on Trans Issues, Stanford, Stanford Encyclopedia of Philosophy, 2014, disponible en http://plato.stanford.edu/archives/spr2014/entries/feminism-trans/ (última fecha de consulta 12 de mayo de 2019), pp. 3948

BOSTROM, N.; "Una historia del pensamiento transhumanista”, en Argumentos de Razón Técnica, n 14, 2011, pp. 186187, en URL https://institucional.us.es/revistas/argumentos/14/art 7.pdf.

BOSTROM, N.; "Why I want to be a posthuman when I grow up", en M. More y N. Vita More The Transhumanist reader: Classical and contemporary essays on the science, technology and philosophy of the human future, Chichester, John Wiley \& Sons 2013.

BRAIDOTTI, R.; Patterns of Dissonance: A Study of Women and Contemporary Philosophy, Cambridge, Polity Press, 1991.

BRAIDOTTI R.; Sujetos nómadas, trad. castellana de A. Bixio, Barcelona, Paidós, 2000.

BRAIDOTTI, R.; Transposiciones: sobre la ética nómada; traducción de Alcira Bixio, Barcelona, Gedisa, 2009.

BRAIDOTTI, R.; Lo posthumano, traducción, Juan Carlos Gentile Vitale, Barcelona, Gedisa, 2015.

CAStro ÁlVAREZ, C.; Los animales y su estatuto jurídico. Protección y utilización de los animales en el derecho, Aranzadi, Cizur Menor, Madrid, 2019.

CORTINA, A; "La pequeña simia", El País, 5 de septiembre de 2016, disponible en el siguiente enlace https://elpais.com/diario/2006/09/05/opinion/1157407205_850215.html (última fecha de consulta 9 de junio de 2019)

DOSSE, F.; Historia del estructuralismo, vol. 1-2, (1992), trad. castellana de M. del Mar Llinares, Madrid, Akal, 2004.

DIÉGUEZ, A; Transhumanismo. La búsqueda tecnológica del mejoramiento humano, Barcelona, Herder, 2017.

FRANCIS, L., SMITH, P.; Feminist Philosophy of Law, Stanford, Stanford Encyclopedia of Philosophy, 2017, disponible en https://plato.stanford.edu/archives/win2017/entries/feminism-law/ (última fecha de consulta 9 de mayo de 2019).

FUKUYAMA, F.; El fin del hombre: consecuencias de la revolución biotecnológica (2002), trad. castellana de P. Reina, Barcelona, ediciones B, 2002.

HALL, M.; The Bioethics of Enhancement, Transhumanism, Disability, and Biopolitics, Lexington Books, London , 2017.

HARARI, Y. N; Homo deus: breve historia del mañana, traducción de Joandomènec Ros, Barcelona: Debate, 2016, p. 381382.

HOU, R.; "Neoliberal governance or digitalized autocracy? The rising market for online opinion surveillance in China". Surveillance \& Society, 2017 15(3/4), pp. 418-424.

JUENGST E.; MOSELEY D.; "Human enhancement" en Stanford Encyclopedia of Philosophy 2019 URL https://plato.stanford.edu/archives/sum2019/entries/enhancement/ consultado el 18 de noviembre 2019.

JUÁREZ, B., “Q; El primer asistente de voz asexual”, El País, 19 de marzo de 2019, disponible en https://elpais.com/tecnologia/2019/03/12/actualidad/1552393305_744375.html (última consulta 11 de junio de 2019)

KYMLICKA, W y DONALDSO; S; Zoópolis, Una revolución animalista, Madrid, Errata Naturae, 2018.

MAHFOUDA, S., MOORE, J.K., SIAFARIKAS, A., ZEPF, F., D., LIN, A., Lancet diabetes and endocrinology; Vol. 5, issue 10, 2017, https:/www.thelancet.com/journals/landia/article/PIIS2213-8587(17)30099-2/fulltext, última consulta 10 de mayo 
MOLINA, A.; "China estrena su "Gran Hermano", La Vanguardia 3 de mayo 2018, https://www.lavanguardia.com/internacional/20180503/443196686690/china-puntuacion-ciudadanos-delitos-sociales.html, última consulta 9 de mayo.

PELluCHON, C.; Manifiesto animalista, Politizar la causa animal, Barcelona, Reservoir Books, 2018

RANISCH R.; SORGNER, L, "Introducing Post- and Transhumanism”, en RANISCH R.; SORGNER, L. (eds.) Post- and Transhumanism. An Introduction, Frankfurt am Main, Peter Lange, 2014.

SANDEL, M.; Contra la perfección, trad. castellana de R. Vilà Vernis, Barcelona, Marbota ed, 2007

SINGER, P., Liberación animal; Madrid, Taurus, 2011.

TALAVERA, P; "De humanos y de simios: la genética y los derechos", Revista de Bioética y Ciencias de la Salud, vol. 2 (2009), pp. 4-16.

VALESINI, S.; "Triptorelina per la disforia di genere anche in Italia: non fa cambiare sesso e salva vite", en wired, 8 de marzo 2018, disponible en https://www.wired.it/scienza/medicina/2019/03/08/triptorelina-disforia-genere/?refresh_ce= última consulta 9 de mayo 2019.

VIDAL LIY, M; “Científicos chinos aseguran haber creado los primeros bebés modificados genéticamente” El País 26 de noviembre de 2018. Disponible en el siguiente https://elpais.com/elpais/2018/11/26/ciencia/1543224768_174686.html (última fecha de consulta 8 de mayo de 2019)

VIOLA, F.; De la naturaleza a los derechos: los lugares de la ética contemporánea, trad. del italiano y estudio introductorio a cargo de Vicente Bellver, Granada: Comares, 1998.

ZUBOFF, S.; The age of surveillance capitalism: the fight for a human future at the new frontier of power, New York, Public Affairs 2019. 